\title{
A multi-layer approach for estimating the Energy Use Intensity on an urban scale
}

\section{Article}

\section{Accepted Version}

Creative Commons: Attribution-Noncommercial-No Derivative Works 4.0

Costanzo, V., Yao, R., Li, X., Liu, M. and Li, B. (2019) A multilayer approach for estimating the Energy Use Intensity on an urban scale. Cities, 95. 102467. ISSN 0264-2751 doi: https://doi.org/10.1016/j.cities.2019.102467 Available at https://centaur.reading.ac.uk/87310/

It is advisable to refer to the publisher's version if you intend to cite from the work. See Guidance on citing.

To link to this article DOI: http://dx.doi.org/10.1016/j.cities.2019.102467

Publisher: Elsevier

All outputs in CentAUR are protected by Intellectual Property Rights law, including copyright law. Copyright and IPR is retained by the creators or other copyright holders. Terms and conditions for use of this material are defined in the End User Agreement.

\section{www.reading.ac.uk/centaur}

\section{CentAUR}

Central Archive at the University of Reading

Reading's research outputs online 


\title{
A multi-layer approach for estimating the Energy Use Intensity on an urban scale
}

\begin{abstract}
Various governments are planning their cities to be climate responsive by reducing the energy consumption and carbon emissions according to different scenarios whilst maintaining good indoor comfort conditions. A robust and reliable tool that can estimate the Energy Use Intensity (EUI) of a city is required. This paper presents a new bottom-up engineering-based multi-layer approach able to analyse the energy performance of existing settlements of every size by retaining as much information as possible about their complexities. The process involves i) creating a 3D model of the urban area, ii) building up templates representing different building characteristics such as functions, the ageband of the buildings and operating schedules, iii) running dynamic thermal simulations and iv) displaying the EUI or total energy demand in the 3D model which can be post-processed for further analysis. This approach offers a flexible simulation process according to various purposes, which is particularly useful in decision-making for urban energy retrofitting or planning for new areas. The hourly high-resolution outcomes would benefit the detailed analysis of energy efficiency strategies in order to achieve carbon reduction. The application of this approach is demonstrated for the case of Yuzhong district in Chongqing municipality, China.
\end{abstract}

Keywords: Energy stock model; bottom-up approach; multi-layer information database; energy retrofit planning

\section{Introduction}

The energy consumption in buildings accounts for about $38 \%$ of the final energy consumption and $33 \%$ of $\mathrm{CO}_{2}$ emissions worldwide (Iea, 2008). Within this context, the major developed countries have set very ambitious energy and greenhouse gas emission reduction targets for the years to come. As an example, in the UK the Climate Change Act dictates a reduction of $\mathrm{CO}_{2}$ emissions above $80 \%$ by 2050 against the 1990 values (Parliament of the United Kingdom, 2008), while in both the EU and US, strict schedules for the construction of nearly zero energy buildings starting from 2020 and 2025 have been set, respectively (EU, 2010) (Office, 2016). In November 2009, China pledged a 40-45\% decrease in $\mathrm{CO}_{2}$ emissions per GDP by 2020 against the 2005 level and is currently launching an 
ambitious 'Green Movement' with the specific aim of developing low-carbon and green buildings (MOHURD, 2013). For achieving these objectives, policymakers take responsibility for the building retrofit programme and the choice of different technological solutions. However, a lack of comprehensive knowledge of the energy consumption in the building sector on an urban-scale is a barrier for policy-makers in terms of building retrofitting and energy policies.

A practical method that could provide information on the building energy consumption at a city/community level is thus desired. Such information could underpin policymaking in urban energy planning and conservation programmes. Modelling building energy consumption on an urban scale is popularly used in obtaining urban energy consumption databases. There are two categories of modelling techniques, namely, top-down and bottom-up approaches (Swan \& Ugursal, 2009). Basically, the top-down approach 'treats the building stock as an energy sink, and does not distinguish energy consumption due to individual end uses'; this means that its outcomes are not able to explain energy consumption in detail, but only on an aggregated level. Top-down models usually include macroeconomic and socioeconomic effects along with some technical specifications of the stock, do not require very detailed data and are generally easier to develop and use than bottom-up models (Kavgic et al., 2010). However, they strongly rely on historical energy-use data and are unable to model the impact of new technologies or climate changes.

On the other hand, the bottom-up approach 'encompasses all models which use input data from a hierarchal level less than a sector as a whole' (Swan \& Ugursal, 2009). In this case, the energy consumption of individual end-uses (heating, cooling, domestic hot water and electric appliances) of representative 'typical buildings' is extrapolated to represent a larger context as a function of their frequency distribution within the stock. In more detail, bottom-up engineering models are able to estimate single energy end-uses stemming from the use of different technologies, climates and even behavioural patterns, and then aggregate them at stock level. However, the drawback of these methods is the large amount of data and the oversimplifications (namely the definition of 'typical' buildings) that they require during the simulation process.

This research presents a new bottom-up engineering approach to acquire building information about the stock and to retain as much information as possible for further urban energy modelling.

This approach is based on different 'layers' of information, namely real building shapes and orientation, templates of different building functions, ages of construction and thermal characteristics, thus allowing a great level of detail when scenario analyses are carried out. The use of hourly dynamic simulations further increases the amount of information useful for policy makers to take informed decisions. 
The approach has been demonstrated in detail for a sample area, namely, the Yuzhong district of Chongqing municipality, China.

\section{Current bottom-up stock modelling approaches}

Reinhart and Davila recently carried out a literature review of urban energy modelling and identified three main steps for creating reliable urban energy models: data input organization, thermal modelling and validation (Christoph F. Reinhart \& Cerezo Davila, 2016). For a bottom-up method, the modelling process usually starts with the definition of 'typical' buildings aimed to resemble the energy consumption of different building types (e.g. low-rise, high-rise, towers, slabs etc.) and their uses (e.g. residential, commercial, educational etc.). Then, different energy modelling techniques can be employed to infer the energy consumption of clusters of existing buildings from typical buildings estimates.

The reviews of Swan and Ugursal (Swan \& Ugursal, 2009) and Kavgic et al. (Kavgic et al., 2010) provide a comprehensive view of the different modelling approaches, usually classified in bottom-up statistical and bottom-up engineering.

Bottom-up statistical models adopt different techniques such as a neural network, conditional demand analysis and regression analysis to estimate the energy use of the stock for each specific end-use (Swan \& Ugursal, 2009). This approach does not rely on any typical building types.

As an example, Howard et al. (Howard et al., 2012) analysed the EUI of the New York City stock (both residential and non-residential buildings) using multiple linear regression analysis of the data gathered from the residential and commercial building energy consumption surveys. Similarly, Mastrucci et al. (Mastrucci, Baume, Stazi, \& Leopold, 2014) relied on publicly-available GIS datasets of natural gas and electricity consumption for the residential stock of Rotterdam, aggregated at postcode areas, to estimate the same figures at the building scale.

Finally, Mikkola and Lund (Mikkola \& Lund, 2014) developed an hybrid statistical-bottom up engineering method for generating spatiotemporal load data - at an hourly time resolution - for both cities where spatial input data is available (Helsinki) or are not (Shanghai). In the last cases, an exponential energy density model with values decreasing when moving from the city centre to the outskirts is used.

On the other hand, bottom-up engineering approaches can be regarded as two types based on typical buildings that can be translated in terms of archetype buildings or sample buildings, respectively (see Figure 1). 


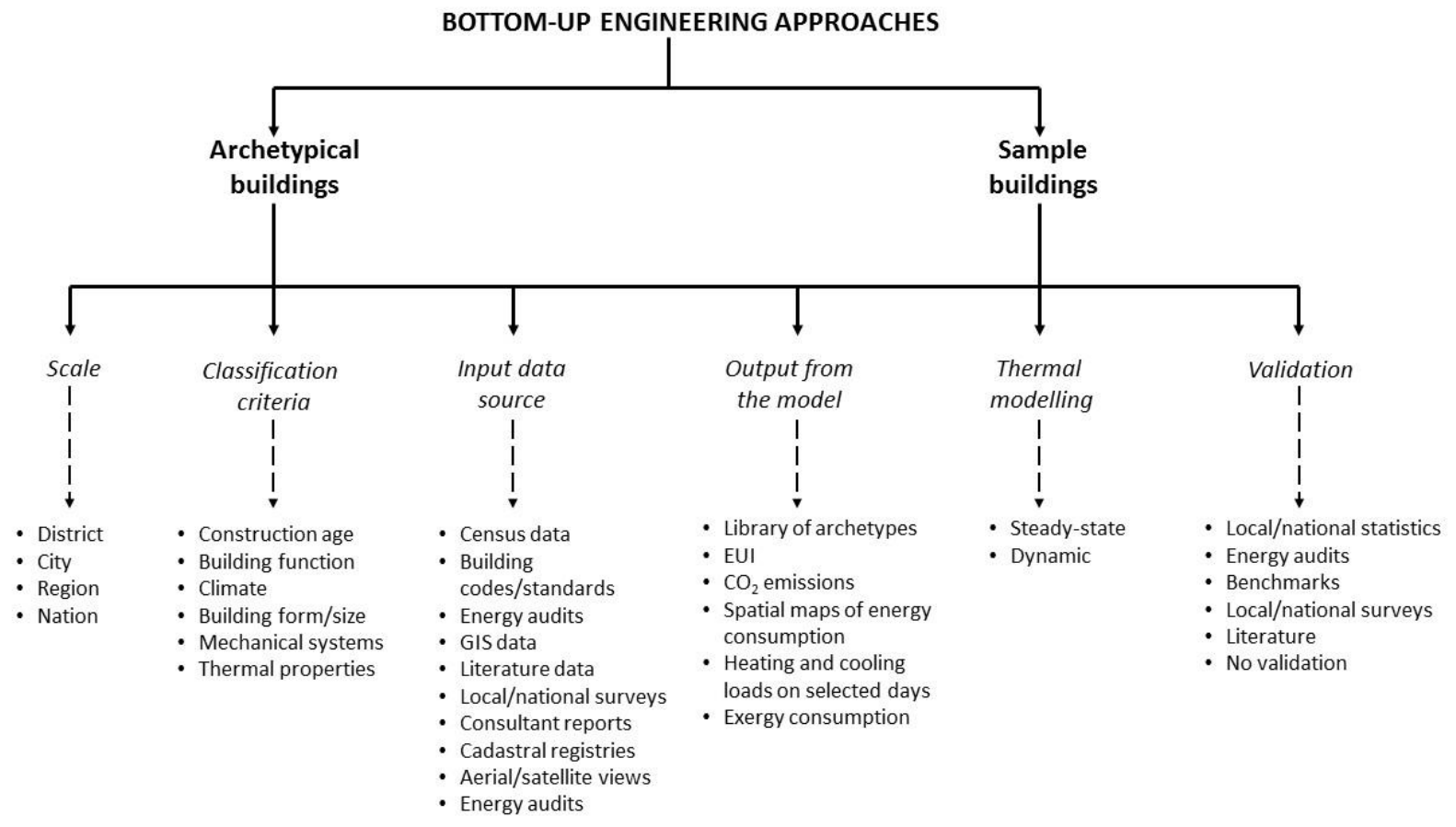

Figure 1. Framework of the categorization of the bottom-up engineering approaches

Archetypes are statistical composites of the features found within the stock, i.e. they are virtual buildings built according to the four steps outlined by Mata et al. (Mata, Sasic Kalagasidis, \& Johnsson, 2014). First, the segmentation process determines the number of archetypes needed to resemble the entire stock to be modelled based on the choice of various parameters. Then, each archetype is fully described (characterization), and weighting coefficients for quantifying the distribution of the archetypes are introduced (quantification). Finally, the validation process compares the simulation results to the actual energy use statistics. This approach needs a large amount of data for the characterization, which comes from extensive surveys or publicly available data. Examples of archetypes developed relying on extensive surveys are those proposed by Parekh for the residential stock in Canada (Parekh, 2005). In this case, data gathered from surveys carried out over the previous 20 years allowed an archetype library useful for implementing future energy policies to be defined, while the actual energy demand has not been estimated. On the other hand, (Huang \& Berkeley, 2000) and (Deru, Griffith, \& Torcellini, 2006) derived an estimate of the heating and cooling energy demand of the US building stock and benchmark commercial building models respectively, based on data collected within the framework of the residential and commercial building energy consumption surveys (RECS, CBECS).

Research that collected input data from publicly-available sources, e.g. (Davila, Reinhart, \& Bemis, 2016), (Ghiassi, Hammerberg, \& Taheri, 2015) and (Fonseca \& Schlueter, 2015), took advantage of existing GIS databases for the analysis of the whole city of Boston, the central area in Vienna and a 
district in Zug (Switzerland), respectively. However, what emerges from these works is that the data still needs to be integrated with other sources such as national norms and standards, experts' knowledge and professional guidelines until energy-oriented GIS databases are fully implemented. Sample buildings are instead defined as existing buildings (not virtual ones) selected to be representative of a percentage of the whole stock when the large amounts of data needed for archetypes are not available. The main issue of using samples is related to the choice of proper selection criteria: (Dall'o', Galante, \& Torri, 2012) selected sample buildings within the small city of Carugate (Italy) based on cartographic information, thematic maps, communal data and the national census. (Theodoridou, Papadopoulos, \& Hegger, 2011) carried out an energy audit of more than 20 existing buildings representative of the multifamily building stock after a statistical analysis concerning the age of construction, technical features, typology-usage, number of floors and occupancy patterns.

\section{Towards micro-scale models}

From the overview of the commonly used approaches, it emerges that the main simplification adopted when defining representative 'typical' buildings of the stock is considering buildings as standingalone. In fact, this brings a series of inaccuracies concerning:

1) Neglecting shading effects on short-wave radiation pattern. Within an urban scenery, solar gains are typically lowered because of the mutual shading of buildings, and consequently heating needs are increased while cooling needs are reduced (Ahn \& Sohn, 2019; Mohammad, Hamdan, \& Oliveira, 2019);

2) Overestimation of the long-wave radiant heat exchange with the sky. The radiant heat exchange with the sky vault, which is a typical passive cooling mechanism of buildings during night time, gets reduced because of lower sky view factors and of mutual radiant heat transfer amongst facades and other urban surfaces (Allegrini, Dorer, \& Carmeliet, 2012; F. S. De La Flor \& Domínguez, 2004; He, Hoyano, \& Asawa, 2009) (Da-long, Hui-hui, \& Jia-ping, 2019; Kotthaus \& Grimmond, 2014; Ramirez, Pasha, Afshari, \& Ramirez, 2019);

3) Incorrect estimate of the surface temperatures facing the canyon. Because of the multiple reflections of solar radiation with the canyons' surfaces, the determination of their temperature is neither trivial nor easily definable without the help of an accurate solar radiation analysis (Strømann-Andersen \& Sattrup, 2011) (V. Costanzo et al., 2018). This has noticeable implications not only in terms of buildings energy balance, but also in terms of outdoor comfort and Urban Heat Island effect (Jihad \& Tahiri, 2016; Perini \& Magliocco, 2014; 
Salata, Golasi, de Lieto Vollaro, \& de Lieto Vollaro, 2016) (Perera, Coccolo, Scartezzini, \& Mauree, 2018; Salvati, Monti, Coch Roura, \& Cecere, 2019);

4) Overestimate of the wind speed. Urban morphology modifies the wind pattern and its magnitude, thus affecting convective heat transfer from the envelope to the outdoor air as well as the natural ventilation potential of buildings (Yang, Zhao, Bruse, \& Meng, 2012) (Memon \& Leung, 2011; Ramponi, Blocken, de Coo, \& Janssen, 2015) (Liu et al., 2018) (Vincenzo Costanzo et al., 2019).

All the above reasons call for the need of what (Frayssinet et al., 2018) recently defined as 'micro simulation', i.e. the explicit simulation of each building within the study domain for the sake of determining the power demand of the cluster. This should be done by adopting an approach that is able to account for the interactions amongst buildings, urban layouts and (preferably) microclimate. One noticeable example in this direction can be found in (Perera et al., 2018). Here the authors developed a modelling approach that, based on a GIS dataset concerning the geometrical features of the city of Nablus (Israel), accounted for urban microclimate modifications using a canopy interface model linked with the CitySim platform to estimate the hourly heating and cooling loads. However, to simplify the complexity found in the real context, the authors studied only selected portions of the city through the definition of representative urban textures (i.e. archetypes).

Similarly, but accounting for a bigger number of archetypes, (Krayem et al., 2019) run hourly EnergyPlus simulations for the city of Beirut (Lebanon). The main limitation of their study seems to be the oversimplifications used for the definition of shading surfaces, which have been selected by means of empirical relationships linked to the height and the distance of surrounding buildings, thus accounting only for the solar direct component and neglecting the direct and diffuse reflected components.

This research work contributes to advance the field of urban micro-simulation by developing a flexible method that overcome these limitations and most of the inaccuracies listed at the beginning of the section, thus furthering the knowledge of urban environments and their energy demand patterns. Details are provided in the following section.

\section{Methodology}

The literature review highlights how previous researchers developed classification methods and modelling techniques tailored to the specific context/object of a study, strongly depending on the availability of reliable data. Although this is true for every context studied, simplifications in both the 
geometric and thermal modelling tasks can lead to significant errors, as previously discussed and rebated also by (Christoph F. Reinhart \& Cerezo Davila, 2016).

Despite this is the common way of operating, as already mentioned the approach here proposed does not make use of typical buildings but rather of different layers of information that allow to overcome most of the oversimplifications usually found in traditional approaches.

The method proposed in this study aims to retain as much information on the existing urban layout as possible, including building form and geometry, thermal properties, the environmental systems and technologies adopted, occupant lifestyles or patterns and so on without the effort of defining archetypes or sampling buildings. Nonetheless, it can be used during the design stage of new settlements to assess the impact of different geometrical configurations (e.g. aspect ratios, compactness ratios, road widths) on EUI.

Dynamic simulation is attempted to obtain high-resolution energy demand profiles. This is particularly beneficial to policymakers and energy suppliers when estimating the effectiveness of energy policies and identifying technological measures and therefore estimating future energy demand and emissions reductions. The new method, namely the multi-layer approach, is built upon the following four steps detailed in the following:

1) Mapping and generating a 3D model of the study area;

2) Defining building templates and attributing building information;

3) Simulating building energy demand;

4) Displaying the results.

\subsection{D model generation}

The generation of a 3D model of the study area is an essential step in urban energy modelling. It presents the real urban configurations and reflects the underlying relationships among different neighbourhood textures such as orientation and shading effects. To accomplish this task, some authors used GIS or LiDAR data when available, or adopted vector machine techniques for semi-automating the process (Caputo, Costa, \& Ferrari, 2013; Du, Zhang, \& Zhang, 2015; Meinel, Hecht, \& Herold, 2009). However, so far, only some cities and regions of the most developed countries (the UK and US for example) have GIS or LiDAR data for non-commercial purposes, and very often this data needs further post-processing in order to be successfully used for creating meaningful 3D thermal models, i.e. models retaining the right Level of Detail (LoD) for thermal simulation purposes (Gimenez, Hippolyte, Robert, Suard, \& Zreik, 2015).

On the other hand, the use of aerial/satellite views is very common and potentially applicable in every context for free. In this study, we chose to use detailed (resolution scale of $20 \mathrm{~m}$ ) and up-to-date (shots 
taken in 2015) Google Maps/Google Earth pictures of the study area. Building footprints can be superimposed in a CAD or GIS environment and any relevant statistics easily inferred, such as footprint areas, perimeter-to-area ratios and other relevant geometrical relationships. These can then be 'layerized', i.e. organized in different layers according to different criteria.

As for building heights and floor-to-ceiling heights, it is possible to infer them by coupling axonometric views in Google Maps/Google Earth with building codes prescriptions concerning floor heights, experts' judgment and local ground surveys.

\subsection{Building templates definition}

For energy simulations purposes, it is necessary to gather information and properties concerning building constructions, the materials used, HVAC systems and their efficiency, and occupancy patterns. Such information could be derived from local or international standards as well as from local surveys.

All these factors depend, to a varying extent, on the specific age of a building. Traditional sources for gathering this information for each building are GIS data, real estate registries and local surveys. Under the assumption that all the buildings built within a certain age band comply with the building codes in force in that period, it is possible to classify them into distinct age bands.

This is obviously a simplification of the reality since it does not take into account the renovation rate of the buildings as well as their refurbishment through time. Nevertheless, if this information is available from other sources, it can be easily fed into the model by creating ad hoc templates (or what is the same other layers) for refurbished buildings.

\subsection{Building energy demand}

The developed multi-layer approach relies on detailed dynamic simulations carried out using a recently-developed Urban Modelling Interface (UMI) (C.F. Reinhart, Dogan, Jakubiec, Rakha, \& Sang, 2013) that has EnergyPlus v8.1 (DOE, 2016) as its core engine.

The tool requires a 3D urban model created or imported within the Rhinoceros v5.0 environment (McNeel 2015), and all the data needed for running traditional hourly EnergyPlus simulations have to be attached to the building templates constructed for every building. The burden of collecting all the data needed is counterbalanced by reduced simulation times. Indeed, UMI uses an algorithm that automatically creates thermal zones named 'shoeboxes' based on the definition of perimeter and core zones as reported in the ASHRAE 90.1 Appendix G (ASHRAE Standard 90.1, 2013) and similar to 
the passive/non-passive area ratio defined in (Baker and Steemers, 2000), as well as on a detailed solar insolation analysis of the facades. The details of this procedure can be found in (Dogan et al., 2013; Dogan and Reinhart, 2015), where validation tests show mean percentage errors in the range of 2-5\% when shoebox models are compared against their traditional EnergyPlus whole-building models, with the tremendous benefit of strongly reduced simulation times. In this way, different scenario analyses are easy to carry out.

\subsection{Result displays}

The high-resolution output of the simulations in terms of EUI (lighting, electric equipment, heating and cooling) can be plotted back in the Rhino 3D model and shown in a false colour scale on the map. This kind of representation is deemed very useful in showing the differences expected for different urban layouts, building types and construction ages, since it is possible to filter the results by the layers previously defined, for example, building types, age band and EUI range values.

Moreover, traditional text files are generated showing hourly and aggregated results of the simulations for each simulated building, so that further post-processing is allowed to present the outputs in a customized way.

A flowchart that summarizes all the steps in a multi-layer approach, together with the input and output data of each of them, is shown in Figure 2.

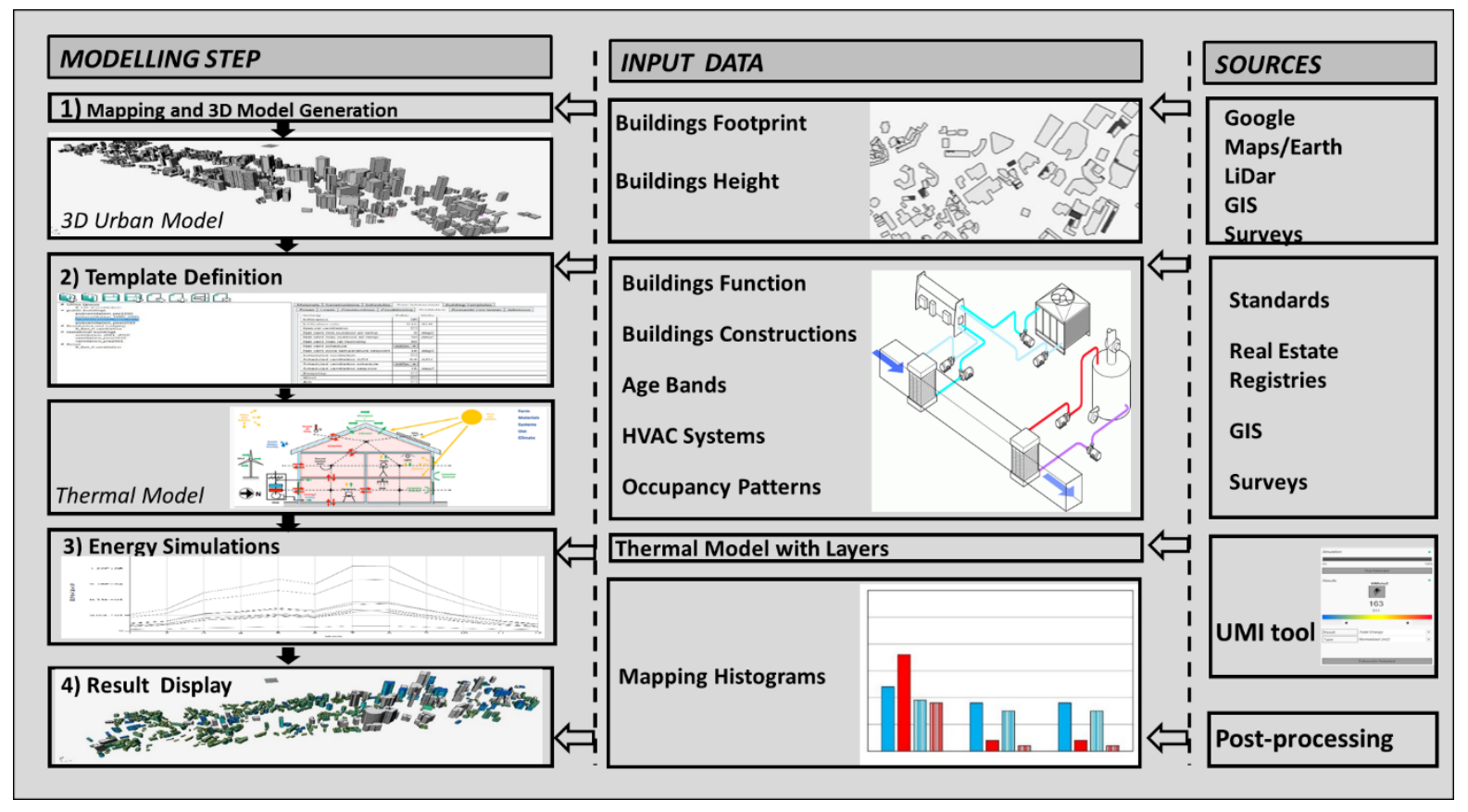

Figure 2. Flowchart of the multi-layer approach for the bottom-up engineering-based modelling 


\section{Application of the method to the Yuzhong district}

The district chosen for demonstrating the method is typical of central business districts in Chinese megacities, characterized by buildings with different shapes, construction ages and technological systems and hosting several different functions. This provides a challenging test bed for assessing the method's capabilities in understanding and quantifying the variety of urban layouts and energy demand patterns.

\subsection{Main characteristics of Chongqing city and the Yuzhong district}

Chongqing belongs to the Hot Summer and Cold Winter (HSCW) climate zone of China in the context of building thermal design (MOHURD, 1993). The main climatic parameters of the area, as gathered from Typical Meteorological Year (TMY) dataset (Wilcox \& Marion, 2008), are summarized in Table 1.

Table 1. Summer and winter daily averages of the main climatic variables

\begin{tabular}{|c|c|c|c|c|}
\hline & $\begin{array}{c}\text { Dry bulb } \\
\text { temperature } \\
\left({ }^{\circ} \mathrm{C}\right)\end{array}$ & $\begin{array}{c}\text { Relative } \\
\text { humidity } \\
(\%)\end{array}$ & $\begin{array}{l}\text { Global horizontal } \\
\text { radiation }\left(W_{h} \mathbf{m}^{-2} \mathbf{h r}^{-1}\right)\end{array}$ & $\begin{array}{c}\text { Wind speed } \\
\left(\mathrm{m} \mathrm{s}^{-1}\right)\end{array}$ \\
\hline $\begin{array}{l}\text { Summer }{ }^{*} \text { (from June } \\
15^{\text {th }} \text { to August } 31^{\text {st }} \text { ) }\end{array}$ & 27 & 79 & 953 & 1.2 \\
\hline $\begin{array}{l}\text { Winter }^{*} \quad \text { (from } \\
\text { December } \quad 1^{\text {st }} \text { to } \\
\left.\text { February } 28^{\text {th }}\right)\end{array}$ & 9 & 86 & 3800 & 1.6 \\
\hline
\end{tabular}

* As defined in the Design standard for energy efficiency of residential buildings in the HSCW zone JGJ 134-2010

(MOHURD, 2010)

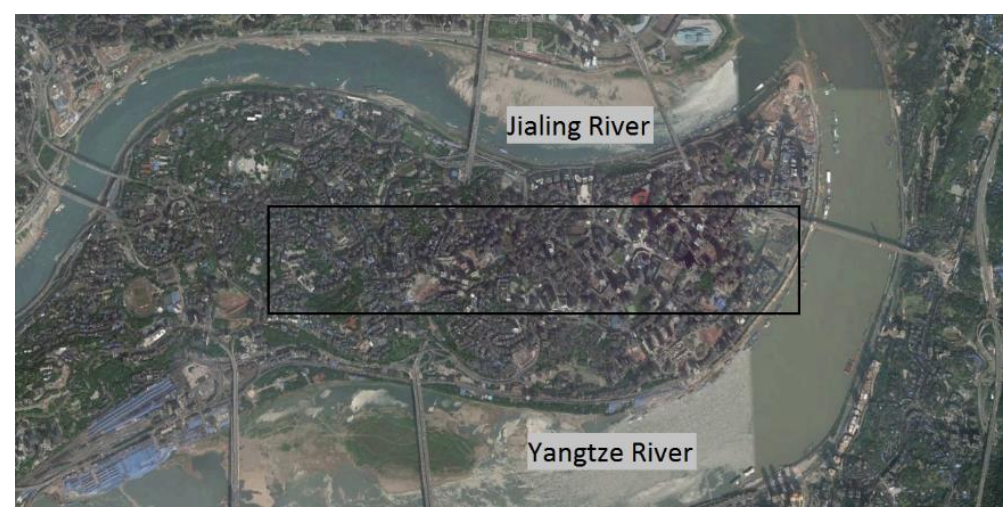

Figure 3. GoogleMap view of the Yuzhong district with the study area highlighted 
As recently highlighted by the local official statistics (NBS, 2014) and reported in Figure 4, the yearly built floor area has continuously increased since the 1990s, and is reaching values almost 4 times higher than 1980s levels for houses and 2 times higher for public buildings. In this study, a ground survey in the Yuzhong district carried out by Chongqing University shows how the largest part of the residential stock was built before 2001 (326 buildings, almost 96\% of the total), i.e. before any energy code came into force in this zone for residential buildings (Figure 5, left side). For public buildings (Figure 5, right side), about a quarter were constructed before 1990 (23 buildings accounting for $122258 \mathrm{~m}^{2}$ of floor area) with a large part of the remainder being built during the period 1990-2005 (68 buildings out of 111). The time classification adopted here considers the national design codes in force in those periods: for residential buildings the 2001 and 2010 codes, while the codes for public buildings were published in 1987, 2005 and 2015.

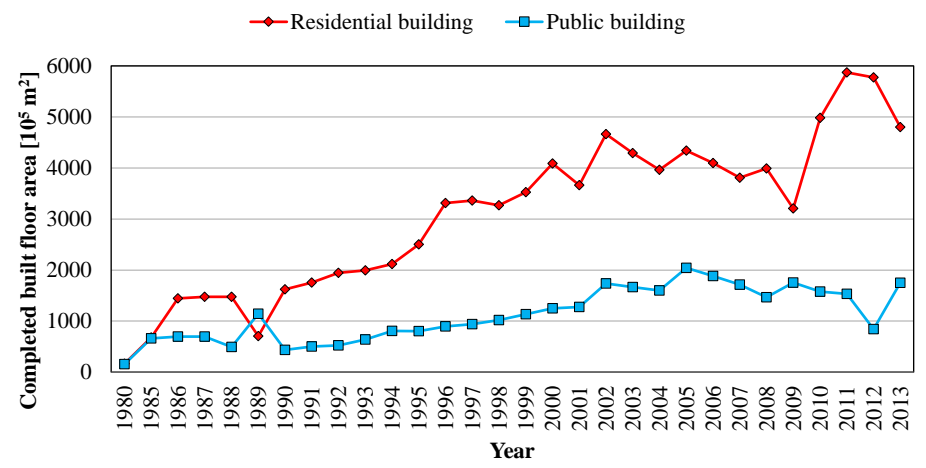

Figure 4. Annually-built floor area in Chongqing (NBS, 2014)

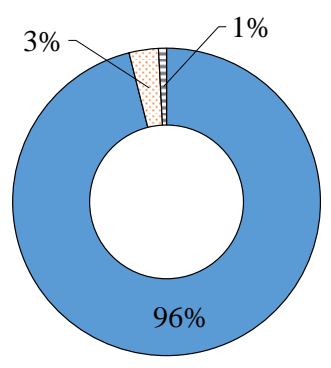

$\square$ before 2001 $\square 2001-2010$ $\boxminus$ after 2010

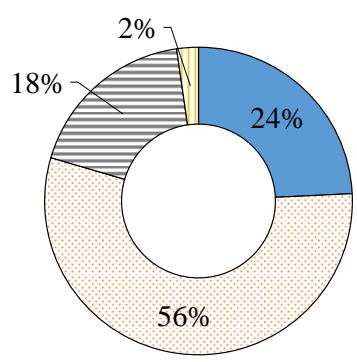

$\square$ before 1990 ㅁ 1990-2005 目2005-2015 $\square$ after 2015

Figure 5. Breakdown of the building stock age for residential (on the left) and public (on the right) buildings in the study area 
The study area has a good mixture in terms of building function: residential accounts for $62 \%$ of the total, mixed-use buildings (i.e. buildings hosting both residential and other uses) $15 \%$ and other nonresidential buildings $22 \%$ (see Figure 6).

Given the range of functions and construction ages found within this zone, as well as the availability of empty spaces for new buildings, this area is deemed to well represent the complexity found in developing Chinese cities and has thus been chosen to demonstrate our modelling approach.
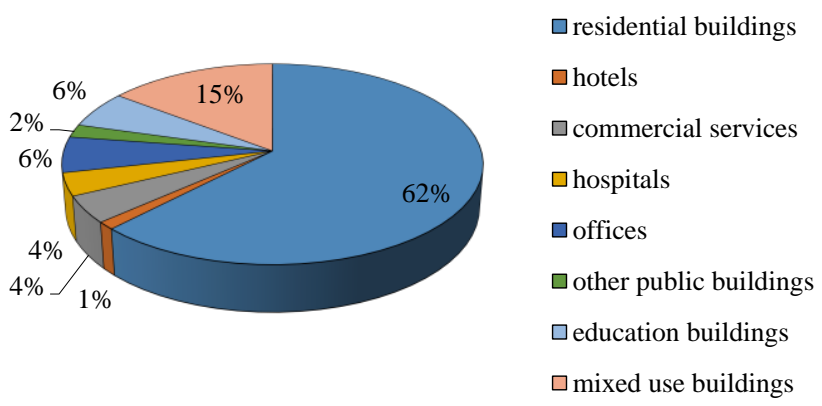

Figure 6. Building functions distribution in the study area

The 3D model, as shown in Figure 7, used in the UMI simulation package, was created based on the built area footprints gathered from Google Maps and the building heights from the ground survey. Here it is possible to appreciate how the tallest buildings (mainly offices and commercial premises) are located in the latest development area of the site (eastern part), while the oldest one mainly hosts residential buildings and some schools.

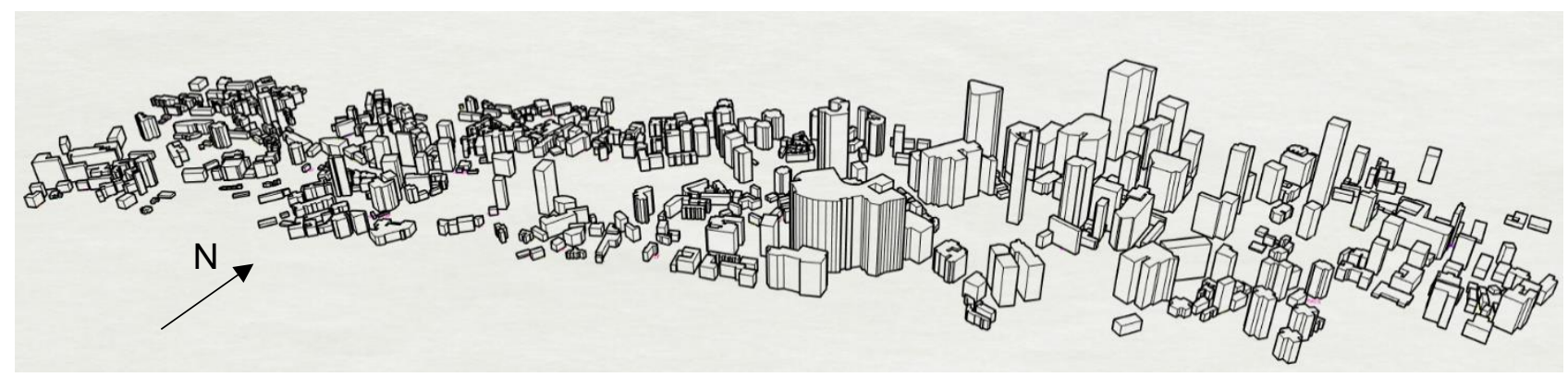

Figure 7. Axonometric view of the 3D model of the Yuzhong district (sample of 544 buildings)

\subsection{Definition of the templates}

The templates used for energy simulations in the UMI platform were mainly based on national and industrial design standards for residential and public buildings (offices, hospitals, educational buildings, commercial buildings and hotels), as summarized in Table 2. For residential buildings, the 
2001 (MOHURD, 2001) and 2010 (MOHURD, 2010) standards were used for the two most recent age bands (2001-2010 and post 2010), while the required data for those built before 2001 was gathered again from (MOHURD, 2001) because its explanation part contains useful information about the oldest residential buildings, for which no further information is available from neither official sources nor scientific literature. For public buildings, the 2005 and 2015 standards (MOHURD, 2005; MOHURD, 2015) were used for the two most recent age bands while for those built before 1990 the data needed was gathered from the explanatory part of the 2005 standard. As we assume that all public buildings in our study area are equipped with air conditioning systems, the building envelope and HVAC system requirements for those premises pertaining to the period 19902005 are gathered from 1987 HVAC standard (MOHURD, 1987). This classification scheme is consistent with previous studies about the building stock in the HSCW zone (Guo et al., 2015; S. Hu, Yan, Cui, \& Guo, 2016; T. Hu, Yoshino, \& Jiang, 2013; Wang, Zhao, Lin, Zhu, \& Ouyang, 2015; Xu, Liu, Pei, \& Han, 2013).

Table 2. Summary of design standards used for creating the templates

\begin{tabular}{|c|c|c|c|}
\hline \multicolumn{2}{|c|}{ Residential buildings } & \multicolumn{2}{|c|}{ Public buildings } \\
\hline pre-2001 & $\begin{array}{l}\text { JGJ 134-2001 } \\
\text { Standard. The } \\
\text { explanatory part } \\
\text { contains } \\
\text { information about } \\
\text { pre-2001 residential } \\
\text { buildings. }\end{array}$ & pre-1990 & 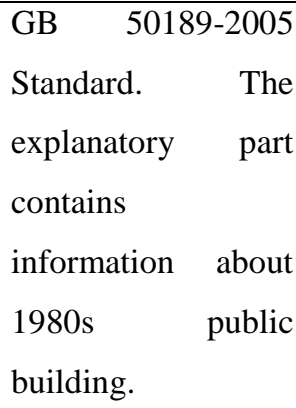 \\
\hline $2001-2010$ & JGJ 134-2001 & $1990-2005$ & GBJ 19-1987 \\
\hline post-2010 & JGJ 134-2010 & $2005-2015$ & GB 50189-2005 \\
\hline & & post-2015 & GB 50189-2015 \\
\hline
\end{tabular}

All the data collected for simulation purposes are shown in detail in the Appendix.

For what concerns the HVAC pattern in residential buildings, occupants are supposed to use mechanical systems during the heating and cooling periods defined in Table 1. Heating is on for an hour in the morning (from 7 to 8 a.m.) and when returning from work (from 6 to 10 p.m.), while due to harsh summer conditions cooling is supposed to be in use $24 \mathrm{~h}$ except when people are out working (from 8 a.m. to 5 p.m.). These schedules have been derived from the survey carried out by (Hu et al., 2013). 
On the other hand, it is assumed that commercial buildings are always air-conditioned throughout the year according to the hourly schedules defined in the standards.

Concerning the constructions used for the opaque envelope, both residential and public buildings are supposed to be built using a concrete frame structure, with outer walls made of solid/cellular clay bricks and roofs and floors made of concrete tiles laid on a mortar layer and on a concrete slab.

In order to approach the U-values prescribed by the Standards listed in Table 2 and reported in the Appendix, layers of different thickness of XPS/EPS insulating materials have been added.

Finally, windows are single-glazed in the oldest age band while being double-glazed with air/argon filling in the latest construction periods. Neither internal nor external shading devices are simulated.

\subsection{EUI distribution for heating and cooling}

It is important to note that it was not possible to validate the simulation results against official statistics concerning the energy consumption breakdown of different building functions and uses in Chongqing because they were not available. This certainly represents a limitation of the study, because as reported in previous research the simulated energy consumption may differ from the actual figures from a minimum of $2.5 \%$ to a maximum of $262 \%$ depending on local climate and district morphological characteristics (Krayem et al., 2019).

However, the energy consumption figures derived with the proposed approach and discussed in the following have been compared to previous modelling and survey studies of both residential buildings (Yao, Costanzo, Li, Zhang, \& Li, 2017), (Guo et al., 2015; S. Hu et al., 2016; T. Hu et al., 2013) and public buildings (Xu et al., 2013) located in Chongqing and show a good agreement.

Furthermore, the method clearly indicates which are the worst and best scenarios and allows drawing comparison amongst different technological solutions, thus providing a sound technical background for planning energy retrofit measures.

The floor-averaged building energy consumption in terms of Energy Use Intensity (EUI) for heating and cooling is summarized in Figure 8 for both residential and public buildings as a function of different age bands. For these premises it is possible to observe how the newest constructions (20012010 and post-2010) perform pretty much the same for both heating and cooling energy demand, and always better than the oldest constructions. In fact, when passing from the oldest to the newest constructions, the expected energy savings are of about $21 \%$ for cooling and of about $88 \%$ for heating thanks to the better performance of both envelopes and HVAC systems.

From Figure 8 it is also possible to see that in the case of public buildings the use of better-insulated envelope components (post-2015 vintage) can reduce the EUI by up to $65 \%$ compared to the oldest constructions with very poor insulation, thus showing a great potential for energy savings and carbon 
reductions. The use of high-efficiency cooling systems (see Appendix B), as well as high internal loads and very low infiltration rates, help keep the energy demand low. Both reasons, together with the fact that public buildings floor area is lower than that of residential buildings, may explain why the EUI of post-2015 public buildings is lower than that of pre-2001 residential buildings.
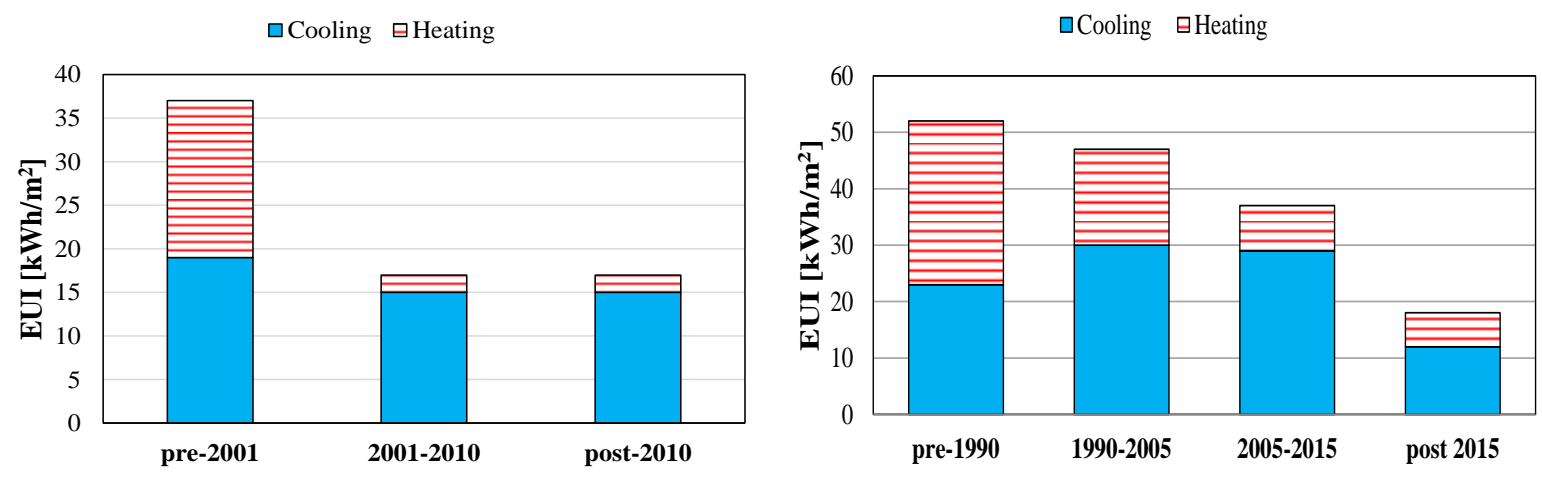

Figure 8. Floor-averaged EUI for residential buildings (on the left) and public buildings (on the right) for different periods

The floor-averaged frequency distribution of the total EUI of residential buildings (on the left) and public buildings (on the right) is plotted as a function of different construction ages in Figure 9.

It is easy to appreciate how important is the role played by different construction technologies and HVAC systems - summarized by different age bands - in determining buildings' energy consumption. For example, the oldest residential dwellings (solid blue line) show an EUI value between $120 \mathrm{kWh} / \mathrm{m}^{2}$ and $140 \mathrm{kWh} / \mathrm{m}^{2}$ whereas the range for the newest one (green and red lines with markers) is lower, being between $105 \mathrm{kWh} / \mathrm{m}^{2}-115 \mathrm{kWh} / \mathrm{m}^{2}$. On the other hand, public buildings' energy demand (Figure 8, right side) is much more spread towards higher values because of both different functions and high internal loads.

This analysis complements the previous one by providing more details on the number of buildings that achieve specific EUI range values, which otherwise could be masked by just using average values. 

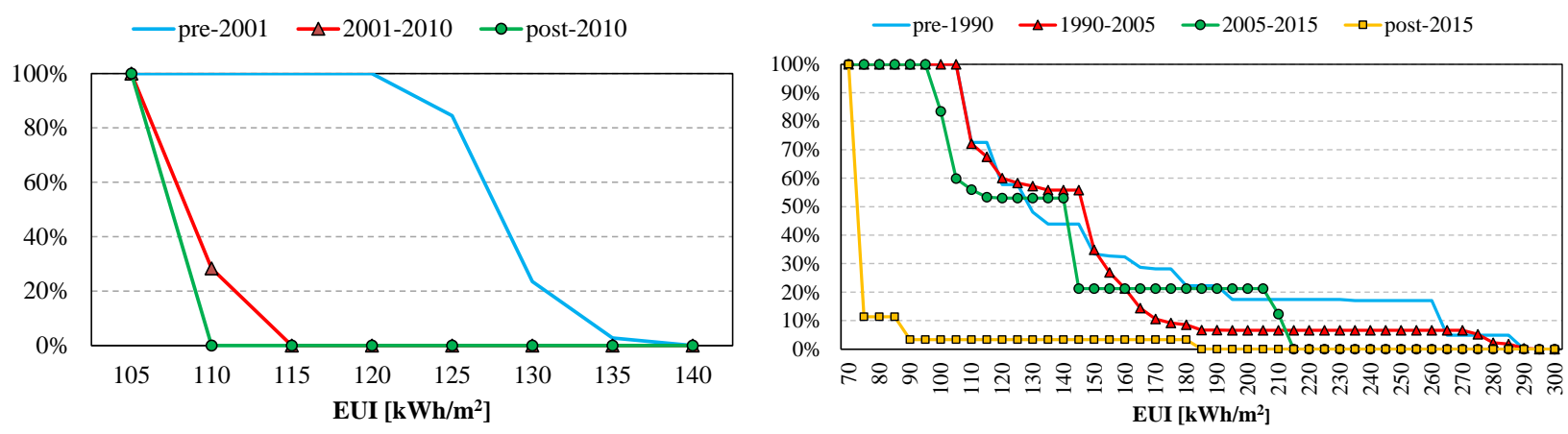

Figure 9. Percentage of floor-area attaining a total EUI value higher than a certain threshold for residential buildings (on the left, S2 case) and public buildings (on the right) for different periods.

\subsection{Total EUI calculation and its spatial distribution}

The cumulative energy use for heating and cooling of the Yuzhong area has been estimated for different functions by summing the results of every modelled building. As expected, residential buildings are the most energy demanding, accounting for about $60 \%$ of the cumulative heating and cooling energy demand (see Figure 10).

Interestingly, cooling seems to represent the biggest challenge because of harsh summer conditions, with a share of $54 \%$ and $63 \%$ of energy consumption in the case of residential and public buildings respectively.

The lower energy consumption expected for public buildings is due not only to the lower number of these premises in the test area, but also to the fact that most of them have been built following more strict requirements than those in force for residential buildings (see both Figure 5 and the Appendix).

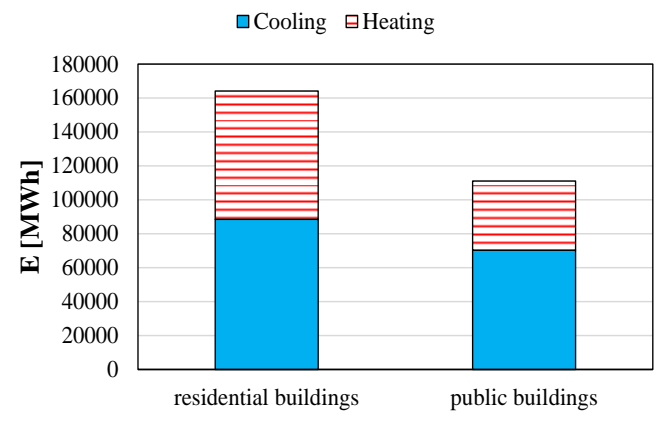

Figure 10. Cumulative energy use for different building functions in Yuzhong district

The resulting carbon emissions, estimated on the basis of these energy figures and by using a conversion factor of $0.5257 \mathrm{~kg}_{\mathrm{CO} 2} / \mathrm{kWh}$ as suggested by (NCSC, 2014), are $86264 \mathrm{tCO}_{2}$ for residential buildings against the $58394 \mathrm{tCO}_{2}$ of public buildings. 
Finally, a 3D visualization of the total energy use intensities accounting for lighting, electric equipment, heating and cooling is provided in Figure 11. Here, shading buildings (i.e. buildings whose EUI have not been calculated because of their mixed function but that are still modelled as likely influences on the energy needs of the surrounding ones) are shown in grey colour, while all the others (residential and commercial) are false-coloured according to the minimum and maximum values estimated from the simulations.

This kind of representation is deemed very useful for showing both the dependence of buildings' energy demand on orientation and geometrical characteristics (building shape and shading effects of the surroundings mainly), as well as on other factors like a building's function and construction period. The results can be further filtered to display only the buildings complying with user-defined criteria, according to the multi-layer approach already described.

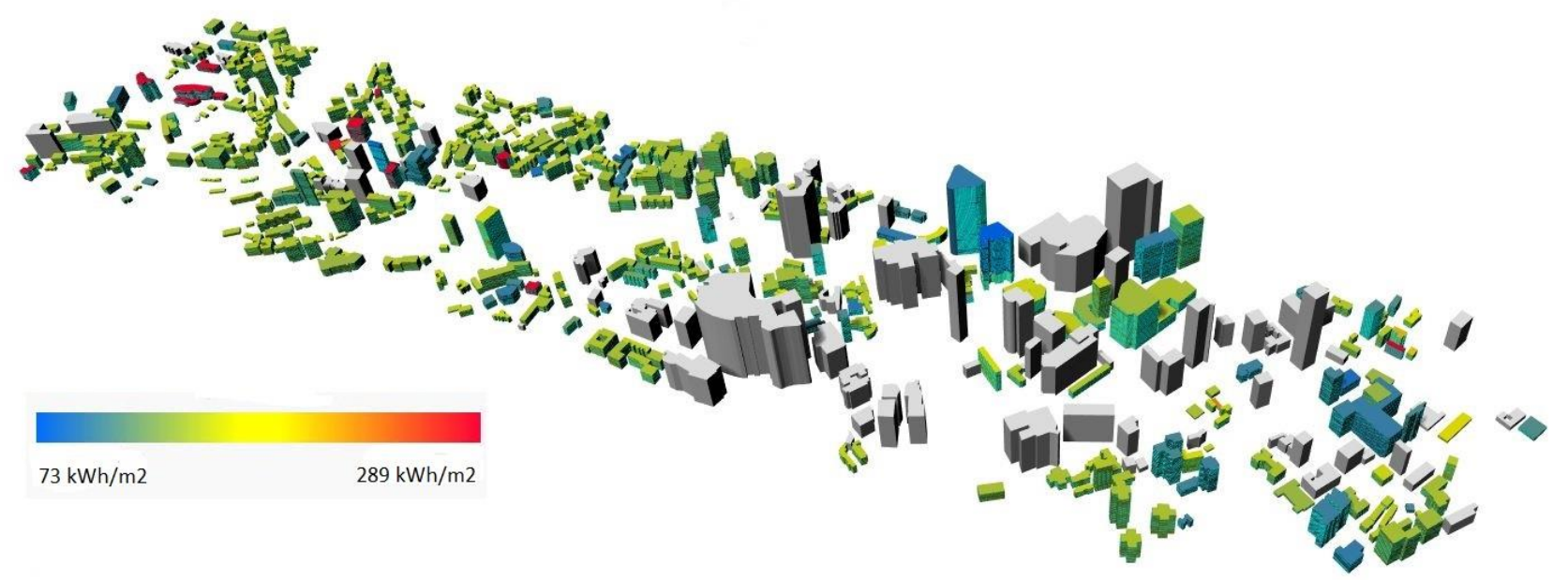

Figure 11. Total energy use intensities distribution within the sample area. The shading buildings are shown in grey.

\subsection{Retrofit scenarios}

To showcase the capabilities of the devised bottom-up approach, a new set of simulations has been run considering two basic retrofit scenarios usually implemented by policy makers concerning residential buildings:

1. Retrofit Scenario A (RS_A): improving the envelope performance of the oldest buildings by using the same constructions and air tightness values of the latest period (post-2010 namely);

2. Retrofit Scenario B (RS_B): replacing the oldest HVAC systems with more efficient devices (i.e. with the corresponding ones of the latest construction period) and improving the envelopes as for retrofit scenario A. 
The implementation of these energy savings measures always brings noticeable benefits for the oldest residential buildings (pre-2001 constructions) as shown in Figure 12. In fact, cooling savings of about $16 \%$ for RS_A and of $21 \%$ for RS_B are expected, while the heating ones amount to $78 \%$ and $89 \%$ for the two scenarios respectively thanks to the lower U-values of the fabric components and to the increased air tightness of the envelope. Because of the similarity in the fabric and HVAC systems adopted by the last two vintages, negligible improvements are expected for the construction period 2001-2010 so these results have not been plotted.

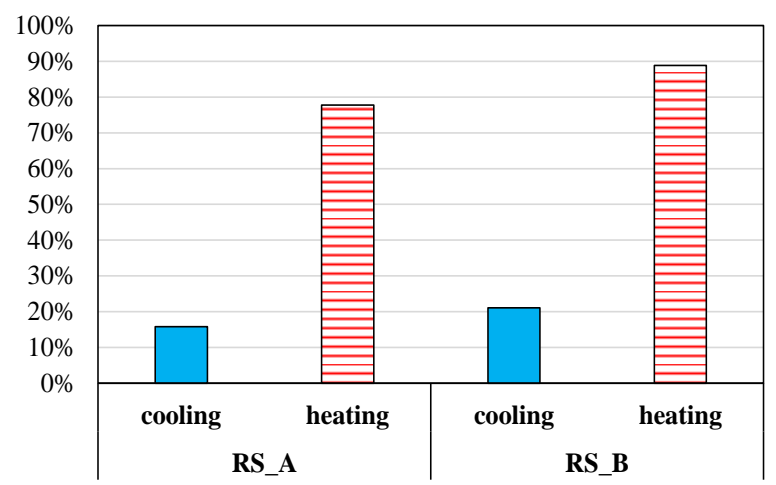

Figure 12. Energy savings due to the implementation of different retrofit scenarios for the oldest pre-2001 residential buildings

The message conveyed by these simulations is that prescribing the existing buildings to be compliant with the latest standard prescriptions in terms of envelope air tightness and U-values can lead to overall energy savings of about $46 \%$ in the case of the oldest residential buildings. Additional savings of around $8 \%$ can be reached if meeting the HVAC systems efficiency requirements set by the latest buildings code.

Public buildings have been excluded from this analysis because the complexity deriving from the very wide range of functions (i.e. hospitals, offices, malls and educational buildings) would require tailored measures and more in-depth knowledge of their operation.

\section{Discussion on the capabilities of the method}

This paper presents a new bottom-up approach able to analyse the energy performance of large urban areas, existing or in the design stage, by retaining a high level of detail at both the building and neighbourhood scales. This approach is defined as multi-layer in both data input collection and output generation since every modelling step is composed of different layers of information, improving building stock energy modelling by adding the following features: 
- Flexibility in the simulation process according to various purposes. Detailed information such as building function, construction age band, thermal properties, occupancy/operation patterns and even climate data can be stored in classified layers. This is particularly useful to the policymakers in decision-making about urban energy retrofitting or planning of new areas;

- Real urban contexts reflecting the actual morphological characteristics of the stock. This overcomes most of the simplifications needed when following the archetype or sampling building approaches;

- Hourly breakdown of different energy use. Such high-resolution outcomes will doubtless benefit the detailed energy efficiency analysis while allowing for scenario analysis that can help policymakers prioritize the retrofit interventions and identify the technologies involved. Furthermore, it helps energy modellers in calibrating urban models when actual energy consumption figures are scarce or not available. In fact, it is possible to filter the simulated energy consumption results by different layers of information (e.g. building function, construction age, EUI range, etc.), and then compare the selected figures only against benchmarks from the literature or available measured data.

Nonetheless, some of the limitations highlighted in Section 3 have not been covered in this paper, namely UHI effects on buildings' energy consumption and altered wind patterns.

As for the first, the UHI phenomenon is on the spotlight of the research community since more than a decade, and some modelling approaches have been already successfully tested (Li et al., 2019). Amongst these, the urban canopy model embedded in the Urban Weather Generator (UWG) can be used for morphing traditional rural TMY datasets into weather data suitable for urban buildings (Nakano, Bueno, Norford, \& Reinhart, 2015). This morphing procedure allows for modification of the air temperature and relative humidity climate variables by accounting for real urban geometric layouts, surface material properties (albedo and thermal emissivity namely), vegetation and anthropogenic heat sources (Bueno, Norford, Pigeon, \& Britter, 2011; Murr \& Prékopa, 2000). The UWG can be easily linked to the method proposed in this research through the UMI platform by referencing the same 3D model via the Dragonfly component freely available in the Grasshopper algorithm editor (Cucchiella \& D'Adamo, 2015), thus reducing the modelling burden from the user's side.

On the other hand, the study of wind patterns in urban settlements is still a challenge for urban energy modelers yet to be solved without the use of accurate CFD simulations (Kotthaus \& Grimmond, 2014; Pacifici, Rama, Regina, \& Marins, 2019). The authors of the current research have themselves studied the natural ventilation potential for passive cooling purposes of the same urban domain analyzed in this research (Vincenzo Costanzo et al., 2019), but could neither link the results obtained nor create 
an integrated modelling approach because of lack of communication between the energy simulation and CFD engines and of computational limitations.

Bridging this gap definitely represents a timely research topic, also in the light of the need for standardizing the data formats required for exchanging the information essential for urban energy modelling.

\section{Conclusions}

A new bottom-up engineering-based multi-layer method to estimate the EUI of urban settlements has been developed, and its potentialities disclosed for the Yuzhong district in Chongqing municipality (China) case study. A flexible modelling process, thanks to the different layers of information that can be stored and easily modified, revealed great opportunities for reducing the energy consumption for heating and cooling of residential buildings when retrofitting according to the prescriptions set by the latest JGJ 134-2010 Standard.

Indeed, reducing the U-value of the envelope components of the oldest pre-2001 buildings down to the values prescribed by the latest standard for constructions built after 2010 would reduce the energy consumption for heating of about $78 \%$ and for cooling of about $16 \%$. Additional savings amounting to around $11 \%$ for heating and 5\% for cooling can be reached if replacing the existing heating and cooling devices of coefficient of performance equal to 1 and 2.2 with others prescribed by JGJ 1342010 Standard and of efficiency equal to 1.9 and 2.3 respectively.

Policy makers and building scientists should thus focus on the definition of specific measures to reduce the cooling energy needs (such as the use of high efficiency air conditioning systems) of both residential and public buildings, since space cooling actually accounts for about $60 \%$ of the cumulative heating and cooling energy consumption in the surveyed area.

Climate change effects, as foreseeable by means of future weather predictions made by international bodies such as the Intergovernmental Panel on Climate Change (IPCC), will represent the object of future research to assess the resilience of Chinese cities. Further research will also be conducted to better appraise the modification of wind patterns in urban settlements, and to link this information to the multi-layer method developed in this research.

Acknowledgements: The authors would like to thank the UK Engineering and Physical Sciences Research Council (EPSRC EP/N009797/1) and the Natural Science Foundation of China (NSFC 51561135002) for their financial support to the Research Project Low Carbon Climate-responsive 
Heating and Cooling of Cities (LoHCool) co-ordinated by Prof. Alan Short, University of Cambridge, UK and Prof. Baizhan Li, Chongqing University, China.

\section{References}

Ahn, Y. J., \& Sohn, D. W. (2019). The effect of neighbourhood-level urban form on residential building energy use: A GIS-based model using building energy benchmarking data in Seattle. Energy and Buildings, 196, 124-133. https://doi.org/10.1016/j.enbuild.2019.05.018

Allegrini, J., Dorer, V., \& Carmeliet, J. (2012). 314 : Impact of urban microclimate in street canyons on building cooling demand predictions. Materials Science, 55, 8-11. https://doi.org/10.1016/j.enbuild.2012.10.013

Bueno, B., Norford, L., Pigeon, G., \& Britter, R. (2011). Combining a Detailed Building Energy Model with a Physically-Based Urban Canopy Model. Boundary-Layer Meteorology, 140(3), 471-489. https://doi.org/10.1007/s10546-011-9620-6

Caputo, P., Costa, G., \& Ferrari, S. (2013). A supporting method for defining energy strategies in the building sector at urban scale. Energy Policy, 55, 261-270. https://doi.org/10.1016/j.enpol.2012.12.006

Catita, C., Redweik, P., Pereira, J., \& Brito, M. C. (2014). Extending solar potential analysis in buildings to vertical facades. Computers and Geosciences, 66, 1-12. https://doi.org/10.1016/j.cageo.2014.01.002

Costanzo, V., Yao, R., Essah, E., Shao, L., Shahrestani, M., Oliveira, A. C., ... Biyik, E. (2018). A method of strategic evaluation of energy performance of Building Integrated Photovoltaic in the urban context. Journal of Cleaner Production, 184, 82-91. https://doi.org/10.1016/j.jclepro.2018.02.139

Costanzo, Vincenzo, Yao, R., Xu, T., Xiong, J., Zhang, Q., \& Li, B. (2019). Natural ventilation potential for residential buildings in a densely built-up and highly polluted environment. A case study. Renewable Energy, 138, 340-353. https://doi.org/10.1016/j.renene.2019.01.111

Cucchiella, F., \& D’Adamo, I. (2015). A multicriteria analysis of photovoltaic systems: Energetic, environmental, and economic assessments. International Journal of Photoenergy, 2015(i). https://doi.org/10.1155/2015/627454

Da-long, L., Hui-hui, Z., \& Jia-ping, L. (2019). Energy \& Buildings Rule of long-wave radiation in 
enclosed building space. Energy \& Buildings, 182, 311-321.

https://doi.org/10.1016/j.enbuild.2018.09.044

Dall'o', G., Galante, A., \& Torri, M. (2012). A methodology for the energy performance classification of residential building stock on an urban scale. Energy and Buildings, 48, 211219. https://doi.org/10.1016/j.enbuild.2012.01.034

Davila, C. C., Reinhart, C., \& Bemis, J. (2016). Modeling Boston: A workflow for the generation of complete urban building energy demand models from existing urban geospatial datasets. Energy, 117, 237-250. https://doi.org/10.1016/j.energy.2016.10.057

De La Flor, F. J. S., Cebolla, R. O., Félix, J. L. M., \& Domínguez, S. Á. (2005). Solar radiation calculation methodology for building exterior surfaces. Solar Energy, 79(5), 513-522. https://doi.org/10.1016/j.solener.2004.12.007

De La Flor, F. S., \& Domínguez, S. A. (2004). Modelling microclimate in urban environments and assessing its influence on the performance of surrounding buildings. Energy and Buildings, 36(5), 403-413. https://doi.org/10.1016/j.enbuild.2004.01.050

Deru, M., Griffith, B., \& Torcellini, P. (2006). Establishing Benchmarks for DOE Commercial Building R \& D and Program Evaluation Preprint. ACEEE Summer Study on Energy Efficiency in Buildings, (June), 12.

Dogan, T., \& Reinhart, C. (2013). Automated conversion of architectural massing models into thermal 'shoebox' models. BS2013: 13th Conference of International Building Performance Simulation Association, 3745-3752. Retrieved from http://www.ibpsa.org/proceedings/BS2013/p_1123.pdf

Dogan, T., Reinhart, C., \& Michalatos, P. (2015). Autozoner: an algorithm for automatic thermal zoning of buildings with unknown interior space definitions. Journal of Building Performance Simulation, 1493(May), 1-14. https://doi.org/10.1080/19401493.2015.1006527

Du, S., Zhang, F., \& Zhang, X. (2015). Semantic classification of urban buildings combining VHR image and GIS data: An improved random forest approach. ISPRS Journal of Photogrammetry and Remote Sensing, 105, 107-119. https://doi.org/10.1016/j.isprsjprs.2015.03.011

EU. (2010). Directive 2010/31/EU of the European Parliament and of the Council of 19 May 2010 on the energy performance of buildings (recast). Official Journal of the European Union, 1335. https://doi.org/doi:10.3000/17252555.L_2010.153.eng 
Evola, G., \& Margani, G. (2016). Renovation of apartment blocks with BIPV: Energy and economic evaluation in temperate climate. Energy and Buildings, 130, 794-810. https://doi.org/10.1016/j.enbuild.2016.08.085

Faggianelli, G. A., Brun, A., Wurtz, E., \& Muselli, M. (2014). Natural cross ventilation in buildings on Mediterranean coastal zones. Energy and Buildings, 77, 206-218. https://doi.org/10.1016/j.enbuild.2014.03.042

Fonseca, J. A., \& Schlueter, A. (2015). Integrated model for characterization of spatiotemporal building energy consumption patterns in neighborhoods and city districts. Applied Energy, 142, 247-265. https://doi.org/10.1016/j.apenergy.2014.12.068

Frayssinet, L., Merlier, L., Kuznik, F., Hubert, J. L., Milliez, M., \& Roux, J. J. (2018). Modeling the heating and cooling energy demand of urban buildings at city scale. Renewable and Sustainable Energy Reviews, 81(March 2016), 2318-2327. https://doi.org/10.1016/j.rser.2017.06.040

Freitas, S., Catita, C., Redweik, P., \& Brito, M. C. (2015). Modelling solar potential in the urban environment: State-of-the-art review. Renewable and Sustainable Energy Reviews, 41, 915931. https://doi.org/10.1016/j.rser.2014.08.060

Ghiassi, N., Hammerberg, K., \& Taheri, M. (2015). An enhanced sampling-based approach to urban energy modelling. BS 2015 - 14th Int. IBPSA Conference, (April 2016), 626-632. https://doi.org/10.1017/CBO9781107415324.004

Gimenez, L., Hippolyte, J. L., Robert, S., Suard, F., \& Zreik, K. (2015). Review: Reconstruction of 3D building information models from 2D scanned plans. Journal of Building Engineering, 2, 24-35. https://doi.org/10.1016/j.jobe.2015.04.002

Guo, S., Yan, D., Peng, C., Cui, Y., Zhou, X., \& Hu, S. (2015). Investigation and analyses of residential heating in the HSCW climate zone of China: Status quo and key features. Building and Environment, 94, 532-542. https://doi.org/10.1016/j.buildenv.2015.10.004

He, J., Hoyano, A., \& Asawa, T. (2009). A numerical simulation tool for predicting the impact of outdoor thermal environment on building energy performance. Applied Energy, 86(9), 15961605. https://doi.org/10.1016/j.apenergy.2008.12.034

Howard, B., Parshall, L., Thompson, J., Hammer, S., Dickinson, J., \& Modi, V. (2012). Spatial distribution of urban building energy consumption by end use. Energy and Buildings, 45, 141151. https://doi.org/10.1016/j.enbuild.2011.10.061 
Hu, S., Yan, D., Cui, Y., \& Guo, S. (2016). Urban residential heating in hot summer and cold winter zones of China-Status, modeling, and scenarios to 2030. Energy Policy, 92, 158-170. https://doi.org/10.1016/j.enpol.2016.01.032

Hu, T., Yoshino, H., \& Jiang, Z. (2013). Analysis on urban residential energy consumption of Hot Summer \& Cold Winter Zone in China. Sustainable Cities and Society, 6(1), 85-91. https://doi.org/10.1016/j.scs.2012.09.001

Huang, Y. J., \& Berkeley, L. (2000). A Bottom-Up Engineering Estimate of the Aggregate Heating and Cooling Loads of the Entire US Building Stock Prototypical Residential Buildings. Proceedings of the 2000 ACEEE Summer Study on Energy Efficiency in Buildings, (August), $135-148$.

Iea. (2008). Worldwide Trends in Energy Use and Efficiency. Iea.Org, 93. https://doi.org/10.1016/j.cirp.2012.05.002

Jakubiec, J. A., \& Reinhart, C. F. (2013). A method for predicting city-wide electricity gains from photovoltaic panels based on LiDAR and GIS data combined with hourly Daysim simulations. Solar Energy, 93, 127-143. https://doi.org/10.1016/j.solener.2013.03.022

Jang, K. H., \& Jung, S. K. (2009). Practical modeling technique for large-scale 3D building models from ground images. Pattern Recognition Letters, 30(10), 861-869. https://doi.org/10.1016/j.patrec.2009.04.004

Jihad, A. S., \& Tahiri, M. (2016). Modeling the urban geometry influence on outdoor thermal comfort in the case of Moroccan microclimate. Urban Climate, 16, 25-42. https://doi.org/10.1016/j.uclim.2016.02.002

Kavgic, M., Mavrogianni, A., Mumovic, D., Summerfield, A., Stevanovic, Z., \& Djurovic-Petrovic, M. (2010). A review of bottom-up building stock models for energy consumption in the residential sector. Building and Environment, 45(7), 1683-1697. https://doi.org/10.1016/j.buildenv.2010.01.021

Kotthaus, S., \& Grimmond, C. S. B. (2014). Energy exchange in a dense urban environment - Part II: Impact of spatial heterogeneity of the surface. Urban Climate, 10(P2), 281-307. https://doi.org/10.1016/j.uclim.2013.10.001

Krayem, A., Al Bitar, A., Ahmad, A., Faour, G., Gastellu-Etchegorry, J.-P., Lakkis, I., ... Najem, S. (2019). Urban Energy Modeling and Calibration of a Coastal Mediterranean City: The Case of Beirut. Energy and Buildings, 199, 223-234. https://doi.org/10.1016/j.enbuild.2019.06.050 
Li, X., Zhou, Y., Yu, S., Jia, G., Li, H., \& Li, W. (2019). Urban heat island impacts on building energy consumption: A review of approaches and findings. Energy, 174, 407-419. https://doi.org/10.1016/j.energy.2019.02.183

Littlefair, P. (2001). Daylight, sunlight and solar gain in the urban environment. Solar Energy, 70(3), 177-185. https://doi.org/10.1016/S0038-092X(00)00099-2

Liu, S., Pan, W., Zhao, X., Zhang, H., Cheng, X., Long, Z., \& Chen, Q. (2018). Influence of surrounding buildings on wind flow around a building predicted by CFD simulations. Building and Environment, 140(February), 1-10. https://doi.org/10.1016/j.buildenv.2018.05.011

Mastrucci, A., Baume, O., Stazi, F., \& Leopold, U. (2014). Estimating energy savings for the residential building stock of an entire city: A GIS-based statistical downscaling approach applied to Rotterdam. Energy and Buildings, 75, 358-367.

https://doi.org/10.1016/j.enbuild.2014.02.032

Mata, É., Sasic Kalagasidis, A., \& Johnsson, F. (2014). Building-stock aggregation through archetype buildings: France, Germany, Spain and the UK. Building and Environment, 81, 270282. https://doi.org/10.1016/j.buildenv.2014.06.013

Meinel, G., Hecht, R., \& Herold, H. (2009). Analyzing building stock using topographic maps and GIS. Building Research \& Information, 37(February 2015), 468-482. https://doi.org/10.1080/09613210903159833

Memon, R. A., \& Leung, D. Y. C. (2011). On the heating environment in street canyon. Environmental Fluid Mechanics, 11(5), 465-480. https://doi.org/10.1007/s10652-010-9202-z

Mikkola, J., \& Lund, P. D. (2014). Models for generating place and time dependent urban energy demand profiles. Applied Energy, 130, 256-264. https://doi.org/10.1016/j.apenergy.2014.05.039

Mohammad, D., Hamdan, A., \& Oliveira, F. L. De. (2019). PT US CR. Energy \& Buildings. https://doi.org/10.1016/j.enbuild.2019.07.028

Murr, M., \& Prékopa, A. (2000). Solution of a Product Substitution Problem Using Stochastic Programming. Probabilistic Constrained Optimization SE - 14, 49, 252-271. https://doi.org/10.1007/978-1-4757-3150-7_14

Nakano, A., Bueno, B., Norford, L., \& Reinhart, C. F. (2015). URBAN WEATHER GENERATOR - A NOVEL WORKFLOW FOR INTEGRATING URBAN HEAT ISLAND EFFECT 
WITHIN URBAN DESIGN PROCESS Massachusetts Institute of Technology, Cambridge , USA Fraunhofer Institute for Solar Energy Systems ISE, Germany SIMULATION ENGINE \& PLATFOR. Building Simulation Conference, 1901-1908.

https://doi.org/10.1016/S1091853104001594

Office, B. T. (2016). Multi-Year Program Plan.

Pacifici, M., Rama, F., Regina, K., \& Marins, D. C. (2019). Urban Climate Analysis of temperature variability within outdoor urban spaces at multiple scales. Urban Climate, 27(November 2018), 90-104. https://doi.org/10.1016/j.uclim.2018.11.003

Parekh, A. (2005). Development of archetypes of building characteristics libraries for simplified energy use evaluation of houses. Ninth International IBPSA Conference, 921-928. https://doi.org/10.1.1.470.363

Parliament of the United Kingdom. (2008). Climate Change Act 2008. HM Government, 1-103. https://doi.org/10.1136/bmj.39469.569815.47

Perera, A. T. D., Coccolo, S., Scartezzini, J. L., \& Mauree, D. (2018). Quantifying the impact of urban climate by extending the boundaries of urban energy system modeling. Applied Energy, 222(December 2017), 847-860. https://doi.org/10.1016/j.apenergy.2018.04.004

Perini, K., \& Magliocco, A. (2014). Effects of vegetation, urban density, building height, and atmospheric conditions on local temperatures and thermal comfort. Urban Forestry and Urban Greening, 13(3), 495-506. https://doi.org/10.1016/j.ufug.2014.03.003

Radhi, H. (2010). Energy analysis of fa??ade-integrated photovoltaic systems applied to UAE commercial buildings. Solar Energy, 84(12), 2009-2021. https://doi.org/10.1016/j.solener.2010.10.002

Ramirez, N., Pasha, Y., Afshari, A., \& Ramirez, N. (2019). ScienceDirect ScienceDirect Increasing the Accuracy of Radiation Heat Transfer Estimation in a Increasing the Accuracy of Symposium Radiation in a on Heat District Transfer Heating and Estimation Lumped Parameter Urban Canopy Models Lumped Parameter Urban. Energy Procedia, 158, 51815187. https://doi.org/10.1016/j.egypro.2019.01.678

Ramponi, R., Blocken, B., de Coo, L. B., \& Janssen, W. D. (2015). CFD simulation of outdoor ventilation of generic urban configurations with different urban densities and equal and unequal street widths. Building and Environment, 92, 152-166.

https://doi.org/10.1016/j.buildenv.2015.04.018 
Redweik, P., Catita, C., \& Brito, M. (2013). Solar energy potential on roofs and facades in an urban landscape. Solar Energy, 97, 332-341. https://doi.org/10.1016/j.solener.2013.08.036

Reinhart, C.F., Dogan, T., Jakubiec, J. A., Rakha, T., \& Sang, A. (2013). Umi - an Urban Simulation Environment for Building Energy Use, Daylighting and Walkability. Proceedings of BS2013: 13th Conference of International Building Performance Simulation Association, 476-483.

Reinhart, Christoph F., \& Cerezo Davila, C. (2016). Urban building energy modeling - A review of a nascent field. Building and Environment, 97, 196-202. https://doi.org/10.1016/j.buildenv.2015.12.001

Robinson, D., \& Stone, A. (2004). Irradiation modelling made simple: the cumulative sky approach and its applications. PLEA - Passive and Low Energy Architecture, Eindhoven, The Netherlands, (September), 19-22.

Salata, F., Golasi, I., de Lieto Vollaro, R., \& de Lieto Vollaro, A. (2016). Urban microclimate and outdoor thermal comfort. A proper procedure to fit ENVI-met simulation outputs to experimental data. Sustainable Cities and Society, 26, 318-343. https://doi.org/10.1016/j.scs.2016.07.005

Salvati, A., Monti, P., Coch Roura, H., \& Cecere, C. (2019). Climatic performance of urban textures: Analysis tools for a Mediterranean urban context. Energy and Buildings, 185, 162179. https://doi.org/10.1016/j.enbuild.2018.12.024

Sarralde, J. J., Quinn, D. J., Wiesmann, D., \& Steemers, K. (2015). Solar energy and urban morphology: Scenarios for increasing the renewable energy potential of neighbourhoods in London. Renewable Energy, 73(August), 10-17. https://doi.org/10.1016/j.renene.2014.06.028

Strømann-Andersen, J., \& Sattrup, P. A. (2011). The urban canyon and building energy use: Urban density versus daylight and passive solar gains. Energy and Buildings, 43(8), 2011-2020. https://doi.org/10.1016/j.enbuild.2011.04.007

Swan, L. G., \& Ugursal, V. I. (2009). Modeling of end-use energy consumption in the residential sector: A review of modeling techniques. Renewable and Sustainable Energy Reviews, 13(8), 1819-1835. https://doi.org/10.1016/j.rser.2008.09.033

Theodoridou, I., Papadopoulos, A. M., \& Hegger, M. (2011). A typological classification of the Greek residential building stock. Energy and Buildings, 43(10), 2779-2787. https://doi.org/10.1016/j.enbuild.2011.06.036 
Wang, Z., Zhao, Z., Lin, B., Zhu, Y., \& Ouyang, Q. (2015). Residential heating energy consumption modeling through a bottom-up approach for China's Hot Summer-Cold Winter climatic region. Energy and Buildings, 109, 65-74. https://doi.org/10.1016/j.enbuild.2015.09.057

Xu, L., Liu, J., Pei, J., \& Han, X. (2013). Building energy saving potential in Hot Summer and Cold Winter (HSCW) Zone, China-Influence of building energy efficiency standards and implications. Energy Policy, 57, 253-262. https://doi.org/10.1016/j.enpol.2013.01.048

Yang, X., Zhao, L., Bruse, M., \& Meng, Q. (2012). An integrated simulation method for building energy performance assessment in urban environments. Energy and Buildings, 54, 243-251. https://doi.org/10.1016/j.enbuild.2012.07.042

Yao, R., Costanzo, V., Li, X., Zhang, Q., \& Li, B. (2017). The effect of passive measures on thermal comfort and energy conservation. A case study of the Hot Summer and Cold Winter climate in the Yangtze River region. Journal of Building Engineering, 15(June 2017), 298310. https://doi.org/10.1016/j.jobe.2017.11.012 


\section{Appendix. Building templates}

\begin{tabular}{|c|c|c|c|c|c|c|c|c|c|c|c|}
\hline \multicolumn{12}{|c|}{ Residential buildings } \\
\hline Vintage & \multicolumn{4}{|c|}{ Envelope $U$-values $\left(W / m^{2} K\right)$} & \multicolumn{2}{|c|}{ Ventilation } & \multicolumn{2}{|c|}{ HVAC } & \multicolumn{3}{|c|}{ Internal gains } \\
\hline & Walls & Roof & Slab & $\begin{array}{c}\text { Windows } \\
(\mathrm{U} \\
\text { value/SHGC) }\end{array}$ & $\begin{array}{l}\text { Infiltrations } \\
(\mathrm{ACH})\end{array}$ & $\begin{array}{l}\text { Fresh air supply } \\
\qquad\left(\mathrm{m}^{3} / \mathrm{s} \mathrm{p}\right)\end{array}$ & $\begin{array}{c}\text { Heating/Cooling } \\
\text { setpoint }\left({ }^{\circ} \mathrm{C}\right)\end{array}$ & $\begin{array}{c}\text { Heating } \\
\text { COP/Cooling } \\
\text { EER (-) }\end{array}$ & $\begin{array}{l}\text { Occupants density } \\
\left(\mathrm{p} / \mathrm{m}^{2}\right)\end{array}$ & $\begin{array}{c}\text { Equipment } \\
\text { density }\left(\mathrm{W} / \mathrm{m}^{2}\right)\end{array}$ & Lighting density $\left(\mathrm{W} / \mathrm{m}^{2}\right)$ \\
\hline Pre-2001 & 1.97 & 1.62 & 3.74 & $5.74 / 0.85$ & 2 & 0.0138 & $18 / 26$ & $1 / 2.2$ & 0.03 & 4.3 & 6 \\
\hline $2001-2010$ & 1.03 & 1.00 & 1.50 & $2.80 / 0.48$ & 1 & 0.0138 & $18 / 26$ & $1.9 / 2.3$ & 0.03 & 4.3 & 6 \\
\hline Post-2010 & 0.83 & 0.80 & 1.31 & $2.67 / 0.34$ & 1 & 0.0138 & $18 / 26$ & $1.9 / 2.3$ & 0.03 & 4.3 & 6 \\
\hline
\end{tabular}

\begin{tabular}{|c|c|c|c|c|c|c|c|c|c|c|c|c|}
\hline \multicolumn{13}{|c|}{ Public buildings } \\
\hline \multirow[t]{2}{*}{ Vintage } & \multirow[t]{2}{*}{ Function } & \multicolumn{4}{|c|}{ Envelope $U$-values $\left(W / m^{2} K\right)$} & \multicolumn{2}{|c|}{ Ventilation } & \multicolumn{2}{|c|}{ HVAC } & \multicolumn{3}{|c|}{ Internal gains } \\
\hline & & Walls & Roof & Slab & $\begin{array}{c}\text { Windows } \\
(\mathrm{U} \\
\text { value/SHGC) }\end{array}$ & $\begin{array}{c}\text { Infiltrations } \\
(\mathrm{ACH})\end{array}$ & $\begin{array}{l}\text { Fresh air supply } \\
\qquad\left(\mathrm{m}^{3} / \mathrm{s} \mathrm{p}\right)\end{array}$ & $\begin{array}{c}\text { Heating/Cooling } \\
\text { setpoint }\left({ }^{\circ} \mathrm{C}\right)\end{array}$ & $\begin{array}{c}\text { Heating } \\
\text { COP/Cooling } \\
\text { EER (-) }\end{array}$ & $\begin{array}{c}\text { Occupants density } \\
\left(\mathrm{p} / \mathrm{m}^{2}\right)\end{array}$ & $\begin{array}{c}\text { Equipment } \\
\text { density }\left(\mathrm{W} / \mathrm{m}^{2}\right)\end{array}$ & $\begin{array}{c}\text { Lighting } \\
\text { density } \\
\left(\mathrm{W} / \mathrm{m}^{2}\right)\end{array}$ \\
\hline \multirow[t]{5}{*}{ Pre-1990 } & Office & \multirow[t]{5}{*}{1.95} & \multirow[t]{5}{*}{1.44} & \multirow[t]{5}{*}{3.79} & \multirow[t]{5}{*}{$5.74 / 0.85$} & \multirow[t]{5}{*}{0.25} & 0.005 & \multirow[t]{5}{*}{$20 / 26$} & \multirow[t]{5}{*}{$0.55 / 3.8$} & 0.25 & 20 & 11 \\
\hline & Hotel & & & & & & 0.008 & & & 0.067 & 20 & 11 \\
\hline & Mall & & & & & & 0.002 & & & 0.33 & 13 & 12 \\
\hline & Hospital & & & & & & 0.004 & & & 0.125 & 20 & 15 \\
\hline & Educational & & & & & & 0.005 & & & 0.25 & 20 & 11 \\
\hline \multirow[t]{5}{*}{$1990-2005$} & Office & \multirow[t]{5}{*}{1.44} & \multirow[t]{5}{*}{0.97} & \multirow[t]{5}{*}{1.88} & \multirow[t]{5}{*}{$5.74 / 0.85$} & \multirow[t]{5}{*}{0.25} & 0.005 & \multirow[t]{5}{*}{$20 / 26$} & \multirow[t]{5}{*}{$0.55 / 3.8$} & 0.25 & 20 & 11 \\
\hline & Hotel & & & & & & 0.008 & & & 0.067 & 20 & 11 \\
\hline & Mall & & & & & & 0.008 & & & 0.33 & 13 & 12 \\
\hline & Hospital & & & & & & 0.004 & & & 0.125 & 20 & 15 \\
\hline & Educational & & & & & & 0.005 & & & 0.25 & 20 & 11 \\
\hline \multirow[t]{5}{*}{$2005-2015$} & Office & \multirow[t]{5}{*}{0.95} & \multirow[t]{5}{*}{0.70} & \multirow[t]{5}{*}{0.97} & \multirow[t]{5}{*}{$2.67 / 0.43$} & \multirow[t]{5}{*}{0.15} & 0.008 & \multirow[t]{5}{*}{$20 / 26$} & \multirow[t]{5}{*}{$0.89 / 4.1$} & 0.25 & 20 & 11 \\
\hline & Hotel & & & & & & 0.008 & & & 0.067 & 20 & 11 \\
\hline & Mall & & & & & & 0.005 & & & 0.33 & 13 & 12 \\
\hline & Hospital & & & & & & 0.008 & & & 0.125 & 15 & 12 \\
\hline & Educational & & & & & & 0.008 & & & 0.25 & 20 & 11 \\
\hline \multirow[t]{2}{*}{ Post-2015 } & Office & \multirow[t]{2}{*}{0.50} & 0.50 & 0.70 & $2.50 / 0.34$ & 0.15 & 0.008 & $20 / 26$ & $0.9 / 4.8$ & 0.10 & 15 & 9 \\
\hline & Hotel & & & & & & 0.008 & & & 0.04 & 15 & 7 \\
\hline
\end{tabular}




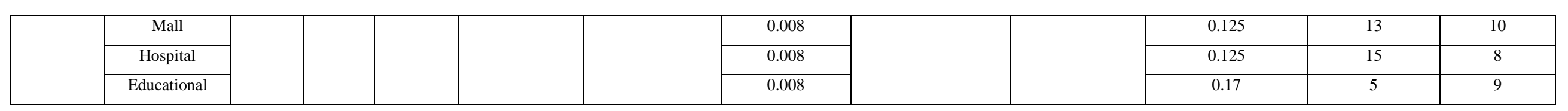

